\title{
Conhecimento pedagógico do conteúdo no ensino de Geometria Elementar: conceito de medida
}

\author{
Débora da Silva de Lara*, José Carlos Pinto Leivas**
}

\section{Resumo}

Este artigo é um recorte de uma dissertação de mestrado que teve por objetivo analisar quais contribuições um espaço de formação continuada de professores de Matemática pode proporcionar à construção do conhecimento pedagógico do conteúdo em Geometria Elementar. A fundamentação teórica do trabalho apoia-se no conjunto de conhecimentos que o professor necessita para o ensino, em especial o conhecimento pedagógico de conteúdo (pedagogical content knowledge - PCK), proposto por David Lee Shulman. Para a realização da pesquisa, contamos com a colaboração de um grupo de seis professores (incluindo a própria pesquisadora), os quais estavam matriculados na disciplina "Matemática nos anos iniciais: conteúdos e produção de atividades do Programa de Pós-Graduação em Ensino de Ciências e Matemática pela Universidade Franciscana". A complexidade do PCK, bem como o fato de esse ser construído em situações reais em sala de aula, dificultou sua construção para os professores que não possuem experiência de ensino nos anos iniciais. Porém, acreditamos ser possível proporcionar-Ihes uma "condição favorável" à construção e ao desenvolvimento do PCK em formações que instiguem esse conhecimento. Como resultado, concluímos que os cursos que exigem do professor reflexão e que contemplam o conhecimento matemático juntamente com o conhecimento pedagógico do conteúdo podem contribuir de forma satisfatória e positiva no ensino e na aprendizagem desse profissional, pois, desse modo, ele não aprende apenas "o que ensinar", mas também "como ensinar".

Palavras-chave: Ensino de Geometria. Formação de professores. Medida.

\footnotetext{
Mestra em Ensino de Ciências e Matemática pela Universidade Franciscana de Santa Maria. Licenciada em Matemática pelo Instituto Federal de Educação, Ciência e Tecnologia Farroupilha - Campus Alegrete. Professora do Colégio Prof. Raymundo Luiz Marinho Carvalho. E-mail: dd.lara@hotmail.com

* Professor do Programa de Pós-Graduação em Ensino em Ciências e Matemática da Universidade Franciscana de Santa Maria. E-mail: leivasjc@unifra.br
} 


\section{Introdução}

O presente artigo é um recorte da dissertação intitulada "Conhecimento pedagógico do conteúdo no ensino de Geometria Elementar: contribuições de um espaço formativo". Tal pesquisa visa analisar as contribuições que um espaço de formação continuada de professores de Matemática pode proporcionar na construção do conhecimento pedagógico do conteúdo em Geometria Elementar. Para a realização da pesquisa, buscamos os pressupostos de Shulman $(1986,1987)$, o qual se concentra em um conhecimento próprio do professor: o conhecimento pedagógico de conteúdo.

De acordo com Shulman $(1986,1987)$, até a década de 1980, as pesquisas didáticas eram voltadas ao conteúdo específico e não à didática envolvida no ensino. A partir dessas questões acerca de metodologias e dificuldades, envolvendo o ensino de cada disciplina específica ou área que compõe o currículo escolar, o autor propõe discussões acerca de conhecimentos que se fazem necessários para que haja o seu ensino: "[...] quais seriam as fontes da base de conhecimentos para o ensino [...]? Como tornar o conteúdo mais compreensível para os alunos?" (SHULMAN, 1986, p. 8). Essas indagações revelam uma preocupação do investigador com o papel do professor ao desenvolver suas aulas e metodologias, a saber: como ensinar esse conteúdo? Puentes, Aquino e Quillici Neto (2009, p. 174), ao se referirem a Shulman, indicam: "Ninguém antes que ele chegou a considerar a existência, no professor, de um conhecimento didático do conteúdo, diferenciado do conhecimento próprio do conteúdo".

Shulman publicou dois artigos, os quais repercutiram em um grande avanço para a formação de professores. São eles: "Those who understand: knowledge growth" (1986) e "Knowledge and teaching: foundations of the new reform" (1987). ${ }^{1}$ Nesses artigos, Shulman resume os conhecimentos que considerava importantes para os professores ao lecionar. Basicamente, para ele, o ensino inicia com a compreensão, por parte do professor, para aprender como ensinar, tendo em vista uma constante continuação nesses saberes (SHULMAN, 1986, 1987). Primeiramente, Shulman (1986) propõe duas categorias essenciais para o conhecimento docente, que são: o conhecimento de conteúdo e o conhecimento pedagógico, detalhando, ainda, o conhecimento de conteúdo em subcategorias, como: conhecimento do conteúdo específico em si, conhecimento curricular e conhecimento pedagógico do conteúdo. 
Ainda, em 1987, Shulman "[...] discursa sobre quais qualidades e profundidade de compressão, habilidades e capacidades, traços e sensibilidades, transformam uma pessoa em um professor competente" (PUENTES; AQUINO; QUILLICI NETO, 2009, p. 173) e define isso como base de conhecimento para o ensino. Ele organiza essas características em sete categorias, isto é: conhecimento do conteúdo; conhecimento pedagógico; conhecimento do currículo; conhecimento pedagógico do conteúdo; conhecimento das características cognitivas dos alunos; conhecimento dos contextos educacionais; e conhecimento dos objetivos educacionais, que incluem propósitos e valores da educação.

Em se tratando do conhecimento do conteúdo, Shulman $(1986,2005)$ sugere que tal categoria extrapola o conhecimento dos fatos ou dos conceitos da área específica. Isso significa que, ao apresentar aos alunos verdades aceitas na Matemática, por exemplo, o professor deverá explicar o motivo pelo qual um resultado é tido como verdadeiro e como tal resultado se relaciona com outras respostas, ou então ressaltar a importância de conhecer essas verdades matemáticas. O professor ainda deve se dedicar a compreender por que um tópico possui um papel tão central na ementa de uma disciplina.

De acordo com Shulman (1986), o conhecimento pedagógico do conteúdo não pode ser adquirido linearmente ou de forma mecânica, como um algoritmo. Para o autor, no entanto, tampouco é um conhecimento que não possa ser ensinado pelas instituições de ensino que formam os professores, já que configura a essência específica do professor, isto é, a dimensão pessoal desse profissional. Nesse sentido, quando compreendemos o conceito de conhecimento pedagógico do conteúdo, na prática, assimilamos de que forma os conhecimentos exercidos pelo professor auxiliam na construção do conhecimento do aluno.

\section{Metodologia}

Para esta pesquisa, em que o tema central se baseia nas concepções de Shulman $(1986,1987)$, desenvolvemos três categorias relacionadas ao conhecimento pedagógico do conteúdo em Geometria Elementar: o conhecimento conceitual de Geometria Elementar, o conhecimento das representações e o conhecimento do recurso didático. Tais categorias surgiram a partir da necessidade de esmiuçar o conhecimento pedagógico do conteúdo dos professores participantes da disciplina: 
Matemática nos anos iniciais: conteúdos e produção de atividades do Programa de Pós-Graduação em Ensino de Ciências e Matemática da Universidade Franciscana.

A disciplina foi ofertada tendo em sua ementa, dentre outros, os seguintes temas: Geometria: espaço, forma, grandezas e medidas; Organização dos espaços: por caminhos topológicos, pelas transformações no plano, pelas medidas, por níveis de desenvolvimento do raciocínio; A percepção em Geometria; A transformação de objetos planos em espaciais e vice-versa. Por ser ofertada pela primeira vez, optou-se pela proposta de pesquisa apresentada neste artigo, uma vez que, a partir dos encaminhamentos advindos da presente pesquisa, novos rumos poderiam ser tomados. A coleta de dados se fez por meio de gravações em vídeo e áudio, questionário, material escrito nos diários de bordo durante o desenrolar da referida disciplina, além das observações da pesquisadora.

\section{Análises}

A partir do tema central, baseado nas concepções de Shulman (1986, 1987), organizamos três categorias ou aspectos relacionados ao conhecimento pedagógico do conteúdo em Geometria Elementar:

a) conhecimento conceitual de Geometria Elementar;

b) conhecimento das representações;

c) conhecimento do recurso didático.

A primeira categoria incluiu conhecimentos específicos da Geometria Elementar. Nessa situação, por exemplo, verificamos como se deu a organização dos espaços no que tange às medidas, ou seja, analisamos o impacto do conhecimento do professor nas transformações de unidades de medida de comprimento, área e volume. A segunda categoria envolveu o conhecimento de como o professor fez a representação do conteúdo de Geometria Elementar, ou seja, quais as estratégias e metodologias que foram utilizadas pelo docente para a possível ampliação dos conhecimentos de seus alunos. Por fim, a terceira categoria esteve ligada ao uso de recurso didático nas atividades, o que incluiu uso de jogos e aplicação de dinâmicas com o grupo de professores pesquisados.

Organizamos essas três categorias como forma de detalhar o conhecimento pedagógico do conteúdo de Matemática e de ressaltar aspectos importantes 
para o ensino e a reflexão de professores de Matemática. Nesse sentido, serão retratados, no artigo, alguns fragmentos que os professores mencionaram no decorrer dos encontros, os quais atribuímos como sendo pontos centrais para cada categoria.

\section{Conhecimento conceitual de Geometria Elementar}

Shulman (1986) afirma que os conhecimentos necessários para ensinar são um amálgama, termo definido, no Dicionário Online de Português (2018, não paginado), como: "Fusão perfeita de coisas ou pessoas distintas que formam um todo; mistura". Dessa forma, cada conhecimento do professor exerce uma influência em outro conhecimento desse mesmo profissional, conforme as categorias (base dos conhecimentos) estipuladas por Shulman. Logo, o conhecimento específico de Geometria Elementar, isto é, o conhecimento conceitual, interfere no conhecimento pedagógico desse conteúdo, pois a associação de ambos tende a contribuir para o alcance dos objetivos específicos com relação à aquisição e à construção do conhecimento geométrico. Essa categoria incluiu os conhecimentos específicos de Geometria Elementar com relação à organização dos espaços no que tange às unidades de medidas de comprimento, área e volume, bem como a comparação desses três aspectos.

No primeiro episódio, ${ }^{2}$ no lugar de exemplos de formas de medir, como a régua, houve a explanação de instrumentos não convencionais, isto é, utilizados em contextos culturais diferentes, como é o caso do palmo, da braça, do mourão ${ }^{3}$ de cerca, do cabo de machado, entre outros. No que se refere ao conteúdo matemático, exercícios envolvendo proporções foram realizados, por exemplo, nas transformações dessas unidades:

Atividade 1 - Efetuar as seguintes transformações de unidades:

a) 01 cabo de machado $\leftrightarrow$ __ palmos

b) 01 palmo $\leftrightarrow$ _ braça.

c) _ mourão de cerca $\leftrightarrow 01$ cabo de machado

d) _ palmo $\leftrightarrow$ cabo de machado

e) 02 braças $\leftrightarrow$ _ mourão de cerca

Foi disponibilizado pelo professor formador $(\mathrm{PF})$ que: o mourão de cerca equivale a 9 palmos; o machado equivale 4,5 palmos; rédeas a 9 palmos; e a braça equivale a 10 palmos. O objetivo da atividade foi que os professores participantes (PPs) 
estabelecessem relação entre essas medidas, bem como que adquirissem alguma familiaridade com elas. Tal tema é próprio da Etnomatemática, ramo interessante e atual da Educação Matemática que envolve os conhecimentos matemáticos de determinadas comunidades.

Em se tratando da resolução desse exercício, Shulman (1986) destaca que, geralmente, o equívoco cometido pelo estudante está relacionado a concepções errôneas. Por isso, é de responsabilidade do professor ter o conhecimento de estratégias que possam readequar ou reorganizar o entendimento do aluno, pois "[...] é muito improvável que esses aprendizes não tenham conhecimentos prévios" (SHULMAN, 1986, p. 12).

Diante disso, percebemos que o conhecimento de um conteúdo específico exige do professor algo além de simplesmente saber resolver problemas ou definir conceitos. De acordo com Mizukami (2004, p. 7),

[...] trata-se de conhecimento de importância fundamental em processos de aprendizagem da docência. É o único conhecimento pelo qual o professor pode estabelecer uma relação de protagonismo. É de sua autoria. É aprendido no exercício profissional, mas não prescinde dos outros tipos de conhecimento que o professor aprende via cursos, programas, estudos de teorias etc. É importante, por fim, que se considere que, embora Shulman não coloque em forma destacada o conhecimento da experiência como uma categoria da base de conhecimento, a experiência está presente em todo processo de raciocínio pedagógico [...] e é condição necessária (embora não suficiente) para a construção do conhecimento pedagógico do conteúdo por parte do professor.

Compreendemos que o conhecimento pedagógico vai além dos saberes quanto aos "conteúdos a serem ensinados", uma vez que também envolve a habilidade do professor de perceber dificuldades de aprendizagem e erros dos alunos, bem como o seu entendimento em um dado momento. Dessa forma, o professor mobiliza diversas formas de representação e argumentos que abarquem o conteúdo específico de sua área. Ademais, essa mobilização de distintas formas de representação é adquirida por estudos, pesquisas e pela prática docente.

Shulman (1986) menciona que o domínio do conteúdo não se baseia em compreender apenas o funcionamento de um determinado assunto, mas também a razão pela qual é assim e, desse modo, quais os fundamentos que são garantidos. No modelo proposto por esse autor, o conhecimento pedagógico dos conteúdos de Matemática inclui a compreensão sobre o que significa ensinar, no nosso tópico de Geometria 
Elementar, assim como o conhecimento sobre os princípios e as estratégias que precisam ser empregados.

$\mathrm{Na}$ atividade 2, foi discutida a questão de medição, partindo das seguintes perguntas: Como medir crescimento? Como saber se uma coisa é maior do que a outra? A seguir, apresentam-se informações registradas pela mestranda a respeito de encaminhamentos feitos pelo PF, bem como as reações dos PPs durante a realização da atividade.

É possível observar que o PF interage com os participantes do grupo, dando a sugestão de usar um aluno como referência e selecionando vários colegas para estabelecerem uma relação entre suas respectivas alturas e a do colega escolhido, indo do visualmente menor para o maior. Do mesmo modo, o PF seleciona outro colega para fazer a relação a partir do mais alto para os mais baixos. Sendo assim, chegou um momento em que os próprios alunos numeraram o colega 1, o colega 2 , o colega 3, e assim sucessivamente, de acordo com sua altura, nos dois modos: alturas crescentes ou decrescentes. Ainda, em uma dada ocasião, o aluno 1 interviu na seleção do colega 2 , alegando que este era mais alto do que o colega 3 , por exemplo. Com essas estimativas, foi possível desenvolver a ideia de "maior que" e "menor que", assuntos presentes no contexto matemático dos anos iniciais, indicando que a atividade se apresentou como pertinente para esse nível de escolaridade.

Um exemplo que o PF mencionou foi o da estimativa sobre as medidas da porta da sala de aula, perguntando qual seria a sua altura aproximada. A professora $\mathrm{C}$ mencionou que ela conhece a própria altura, então, a partir dela, teria uma "base" para estimar a altura da porta. Os PPs da atividade colocaram-se no lugar do aluno, imaginando e tentando identificar a medida da porta, bem como estabelecendo comparativos no sentindo de estimativas de comprimento. Esse exercício foi muito estimulante, tendo sido constatado que a maioria não consegue estimar essa medida, muito embora ela seja de uso comum. Isso deveria ser de conhecimento de pessoas adultas, não de crianças pequenas, o que indica ser uma atividade instigante para o ensino de medidas nos anos iniciais.

Na sequência, o PF buscou identificar entre os PPs da pesquisa sobre o entendimento da palavra "medir", lançando a pergunta: O que é medir? No Quadro 1, seguem as respostas de alguns desses professores. 
Quadro 1 - O que é medir?

Descrição da cena: o PF pergunta para os PPs seu entendimento sobre medir.

Professor B: quantificar.

Professora C: comparar.

PF: comparar com o quê?

Professor B: unidade padrão.

PF: o que é unidade padrão, eu quero comparar o metro com ano, eu posso comparar? Tem como?

Professor B: nenhuma.

PF: eu posso comparar, mas comparar o quê?

Professor B: mesmas grandezas.

Fonte: dados da pesquisa, 2019.

Como mostrado no diálogo, o professor deve ouvir os alunos, escolher perguntas e exemplos que considere adequados para a construção de um conceito em sala de aula, nesse caso, o de medida. No entanto, para que o aluno obtenha uma compreensão da Matemática, o docente deve usar de boas perguntas, as quais poderão levar o aluno ao entendimento desse conceito. Por exemplo, conforme a linha 3 do Quadro 1, o PF pergunta: "comparar com o quê", ou seja, medir não é simplesmente comparar, mas comparar com "alguma coisa", isto é, com uma unidade padrão.

No que diz respeito à função do professor, Serrazina (2012, p. 272) indica que ele deve escolher modelos e exemplos que considere mais adequados à situação vivenciada no contexto escolar, isto é, "[...] para o professor exercer, de modo consciente esta função, tem de ter uma profunda compreensão da Matemática que ensina e conhecer um leque alargado de recursos e materiais”. Um desses materiais, usado nessa formação a fim de detalhar o conceito de unidade padrão para medir, foi um trecho do livro O homem que calculava, de Malba Tahn (1999, p. 49): "É mais fácil uma baleia ir a Meca, em peregrinação, do que [...] Moharrã aprender Matemática [...]". O texto salienta algumas comparações, o que, no primeiro momento, os PPs não compreenderam. Em vista disso, o PF mencionou outras comparações que podem ser feitas para a compreensão de "comparar".

O conhecimento pedagógico de conteúdo de Matemática, nesse momento da aula, pôde ser entendido como a capacidade de representar o conteúdo de Geometria Elementar, isto é, da forma com que o professor reorganiza a atividade, ou o 
que fora dito, de forma que o aluno compreenda o que ele está buscando identificar com ele, já que os PPs não obtiveram entendimento da ideia presente no trecho do livro. Por isso, o PF destacou outras analogias, como, por exemplo, que não se pode comparar metros com anos, pois não são grandezas de mesma natureza. Esse exemplo provocou a compreensão pelo grupo de professores.

É válido destacar que o conhecimento pedagógico do conteúdo, de acordo com Mizukami (2004, p. 6), “[...] é uma forma de conhecimento de conteúdo”, o que diz respeito ao saber pedagógico. Isso significa transformar esse saber, além do conteúdo específico, de forma que ocorra a aprendizagem. Além disso, para medir, é necessário comparar grandezas de mesma espécie. É claro que, para acontecer a assimilação do conceito, o professor precisa conhecer técnicas e princípios para o ensino, fazendo escolhas adequadas de acordo com a população a que se destina, o que mostrou sua pertinência para a situação de ensino e aprendizagem da disciplina.

Dando sequência às análises, outro tópico explorado diz respeito às representações que o grupo de professores de Matemática usou para as atividades, bem como a maneira pela qual esses professores compreenderam os conceitos abordados nesse espaço formativo.

\section{Conhecimento das representações}

$\mathrm{Na}$ categoria conhecimento das representações, consta a representação de um conteúdo específico de Geometria Elementar, na qual se buscou saber quais as estratégias e metodologias presentes e quais as discussões envolvidas com o grupo de professores em formação continuada em um curso de pós-graduação em ensino.

No primeiro momento da aula, o PF remeteu aos estudos de Chevallard (2005) com a transposição didática - do saber sábio ao saber ensinar -, em que sua teoria conduz a uma forma didática de pensar e refletir sobre o distanciamento que existe entre conteúdos abordados, a realidade em que o aluno vive e a origem do conhecimento para ensinar (Quadro 2). Chevallard (2005), após o movimento da Matemática moderna, começou a discutir várias possibilidades teóricas de como ocorre o ensino em que possibilite a didática. 
Quadro 2 - O que os estudos de Chevallard expressam?

Descrição da cena: o PF traz referência dos estudos de Chevallard, com respeito a saberes.

1. PF: saber ensinar- tem que ver qual é o objeto necessário para saber ensinar, e isso aí está intimamente ligado exatamente com o objeto de ensino. Então há várias distinções entre essas coisas que a gente tem dificuldade em compreender, o que se quer colocar. As coisas são muito parecidas, existe um objeto, o objeto "saber o ensino" e o objeto de "ensino" justamente para estabelecer a correlação entre o saber ensinar e o objeto que tenho que ensinar. Isso é o que chamamos de criações didáticas, e essas são justamente as criações geradas pelas necessidades de ensino [...]. Como vou trabalhar o ensinar do objeto? É necessário que se crie noções, criações.

Fonte: dados da pesquisa, 2019.

O PF ainda apresentou nova explanação sobre o que é o saber sábio e o saber ensinado, conforme consta no Quadro 3.

Quadro 3 - O que são saberes?

Descrição da cena: explicação do PF sobre "saberes"

2. PF: Saber ensinado- ele conduz ao que vai encontrar. Vai ter de buscar junto ao aluno.

Saber sábio - é justamente aquele saber matemático. Esses dois saberes são duas coisas distintas e, por serem diferentes, há algum distanciamento entre eles. A Matemática dos matemáticos tem um cunho e a do educador matemático tem outro cunho, as duas coisas não chegavam a conversar, e então, fazer o ensino nas universidades, pincipalmente, era muito complicado, porque os "mestres e doutores" com uma excelente formação matemática pouco conseguiam contribuir com essa formação matemática para chegada ao ensino. Tu podes ser um grande especialista nessa área, mas só vais te tornar de fato um professor em um curso de Matemática Pura; a transposição didática vem justamente para buscar amenizar isso, ou seja, no momento que se faz criações didáticas é que se consegue transformar aquele conhecimento, aquele saber sábio, aquele saber do matemático, em um saber a ensinar. Então se consegue chegar ao desejado.

Fonte: dados da pesquisa, 2019.

O saber sábio e o saber ensinado são conhecimentos advindos de formas distintas, ambos importantíssimos para a Matemática, porém o objetivo do conhecimento matemático deve ser preservado, por isso existem discussões em cursos de formação de professores a respeito. Se o objetivo de tais cursos é formar professores, o que se espera na ementa da grade curricular são disciplinas que abarquem propostas, estratégias e metodologias, as quais o professor de Matemática precisará quando for exercer sua profissão.

Diante de tais argumentações sobre o saber sábio e o saber ensinado, podemos alinhar com o que remete o conhecimento pedagógico do conteúdo. Conforme Shulman (2005), a ação de ensinar não se baseia na ação de transmitir conceitos, 
mas em um ofício complexo, no qual é exigido da profissão docente o domínio de conhecimentos específicos, ou seja, de uma área em si e do didático. Por isso, o conhecimento é destacado no seguinte sentido:

[...] la clave para distinguir El conocimiento base para la enseñanza está em la capacidad de um docente para transformar su conocimiento de la matéria em formas que sean didácticamente impactantes y aun así adaptables a clã variedad que presentan sus alunmnos em cuanto a habilidades y bagajes (SHULMAN, 2005, p. 21).

Com respeito à Etnomatemática, o $\mathrm{PF}$ solicitou ajuda de um aluno para medir o comprimento do quadro negro da sala de aula, utilizando seu palmo como unidade de medida. Chamamos essa dinâmica de "atividade 3". Além disso, o PF realizou a mesma mediação, utilizando como unidade de medida o seu próprio palmo. As representações dessas medições mostraram os valores de 12,5 palmos (participante voluntário) e 12 palmos (PF), contatando-se a diferença de medição de ambos em virtude das unidades de medidas diferentes. Entretanto, o quadro negro medido tem um comprimento único, o qual pode ser traduzido ou representado por quantidades diferentes. O PF salientou para os participantes: "Imagine em sala de aula, o quão interessante seria essa atividade!".

$\mathrm{Na}$ atividade 3, foi solicitado que todos os PPs medissem com a régua o comprimento de seu próprio palmo em centímetros. Nesse sentido, os PPs mencionaram a empolgação que esse experimento proporcionaria em sala de aula, já que a medida em palmos pode ser diferente da medida do palmo do outro colega e, com isso, poderia gerar uma discussão saudável. 
Figura 1 - Aluno e professor medindo o quadro negro com a unidade de medida palmo
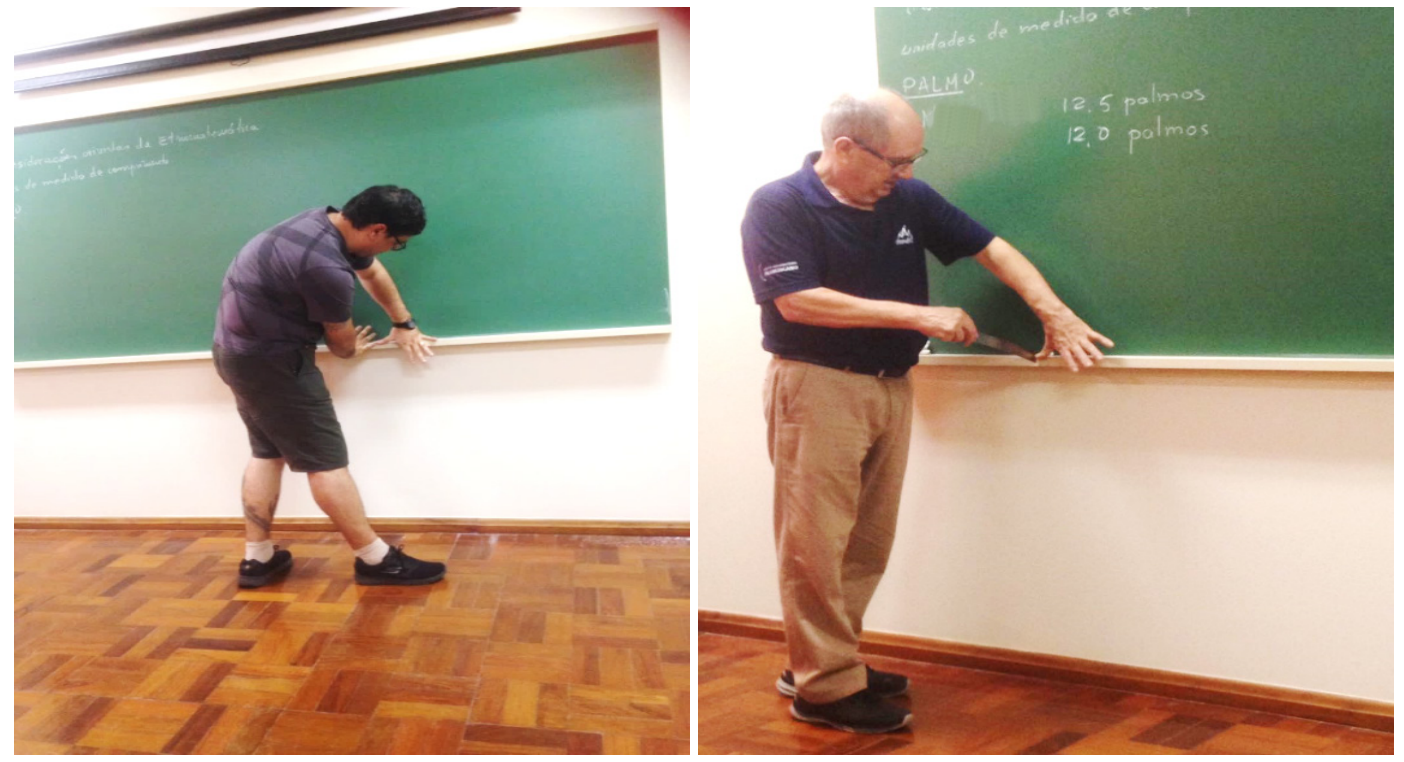

Fonte: dados da pesquisa, 2019.

Com relação às interações ocorridas em sala de aula, como foi este experimento, o PF assumiu um papel fundamental, pois, de acordo com Ponte e Serrazina (2000, p. 111), existem duas maneiras de o professor comportar-se nesse contexto:

[...] em uma, o professor introduz os conceitos e o conhecimento matemático na sua forma acabada e os alunos têm essencialmente um papel de receptores de informação.

Na outra, o saber é construído pelos alunos no decurso da própria atividade, assumindo assim uma participação ativa, e o professor tem essencialmente um papel de organizador e dinamizador da aprendizagem.

Em ambas as situações, as interações ocorreram com rumos distintos, e essa distinção se deu pela relação que o PF atribuiu ao seu conhecimento e à maneira pela qual conduziu essas interações.

Com relação ao conhecimento que o aluno já tem, a tarefa da atividade 4 consistiu em mostrar outra ferramenta de medida: o mourão de cerca, que equivale a 9 palmos. A professora $\mathrm{F}$ desconhecia essa medida, então a professora $\mathrm{D}$ explicou como são feitas as cercas na zona rural, ou seja, são postes de madeira, posicionados verticalmente, em determinados espaçamentos. O PF explicou que se trata de um conhecimento importantíssimo que o professor tem para apresentar aos alunos que 
moram na zona rural como os seus pais fazem as cercas que limitam terras e loteamentos, bem como aos alunos que moram na cidade e desconhecem como funciona a educação no campo ou como trabalhadores usam esse conhecimento para um fim específico. Com respeito à educação no campo, a professora $\mathrm{D}$, que conviveu nesse contexto, mencionou a quadra de arroz, argumentando outras formas de medidas.

Por conseguinte, acreditamos que o conhecimento pedagógico do conteúdo não está vinculado apenas ao entendimento do conteúdo em si. Em vez disso, ele visa compreender e organizar os processos de produção do conteúdo, bem como a relação entre tópicos de áreas distintas. $\mathrm{O}$ conhecimento pedagógico do conteúdo está intimamente ligado à visão do conhecimento específico do conteúdo como um conhecimento a ser ensinado, que engloba a forma de abordá-lo para que os alunos o entendam. Nesse contexto, o professor deve saber "como ensinar" o tópico, de forma que seja compreensível para os alunos. Esse conhecimento envolve as concepções e crenças que os estudantes possuem sobre a disciplina. Shulman (1992) ainda atribui esse saber às capacidades de improvisação, julgamento, intuição e raciocínio e ação pedagógica, as quais possibilitam ao docente a elaboração de um plano de ação que seja capaz de improvisar e ensinar num determinado contexto.

Sendo assim, esse conhecimento inclui o conhecimento das concepções prévias que os alunos possuem de determinados conteúdos, com o intuito de selecionar as melhores estratégias para resolver um problema. O próximo aspecto a ser considerado nesse episódio refere-se ao conhecimento do recurso didático no espaço de formação continuada para professores em que o estudo foi desenvolvido.

\section{Conhecimento do recurso didático}

Ao mencionar o conhecimento de recursos didáticos para o ensino de Matemática no currículo escolar, Shulman (1986, p. 13) destaca que:

[...] quantos indivíduos dos quais nós preparamos para ensinar [...] entendem bem os materiais para essa instrução, os textos alternativos, softwares, programas, materiais visuais [...], demonstrações laboratoriais, ou "convites para pesquisa"? Nós confiaríamos em um médico que não entendesse realmente das formas alternativas de lidar com categoriais de doenças contagiantes, e que só soubesse de uma forma?

Os recursos didáticos, como apoio educacional, estão presentes no cotidiano escolar, cabendo ao professor estabelecer uma união entre eles e o ensino de Matemática, especificamente, o de Geometria para os anos iniciais. Dentre as atividades 
relatadas nesta pesquisa, tem-se o "jogo de bolinhas", explorado durante a aula. A seguir, será apresentada a atividade 5 e sua resolução pelos professores.

\section{Jogo de bolinhas de isopor}

De acordo com os estudos de Piaget (1977), nos jogos de bolinhas de gude, com regras definidas, são apontados quatro níveis na prática das regras elaboradas. Destacam-se:

a) Nível 1: as crianças com idades menores do que 3 anos manipulam os objetos do jogo a partir de seus desejos e de sua coordenação motora. Elas não se intimidam ou se submetem às regras por muito tempo, ou seja, o jogo se caracteriza pela ausência de regras fixas e obrigatórias.

b) Nível 2: as crianças com idades variadas entre 3 e 5 anos brincam com as bolinhas de maneira mais ou menos fixa, tentando seguir regras ou parte delas, sem mesmo compreendê-las muito bem. Enquanto brincam, mesmo juntas, seguem regras diferentes, sem a preocupação de ganhar o jogo.

c) Nível 3: as crianças com idades próximas aos 8 anos coordenam o jogo a partir de regras e passam a se interessar por ganhar, compreendendo que devem ser seguidas tais regras para haver um único vencedor.

d) Nível 4: em geral, é atingido pelas crianças com idade aproximada aos 12 anos, as quais procuram dominar as regras estabelecidas, antever possíveis resultados e encontrar os casos não previstos por elas.

Com o intuito de estimular o processo de contagem, foram expostas as seguintes regras, antes do episódio a ser realizado:

a) Regra 1: solicitar que os alunos tragam bolinhas de isopor na próxima aula, na qual seria realizada a atividade;

b) Regra 2: o aluno que não trouxer perde o jogo;

c) Regra 3: o jogo é em duplas ou trios;

d) Regra 4: perde um ponto o aluno que pular sua vez;

e) Regra 5: ganha o jogo o aluno que obtiver mais pontos, após um tempo determinado;

f) Regra 6: ganha dois pontos o aluno que atingir a bolinha no colega (do espaço $\mathrm{x})$.

Para a realização da atividade, o $\mathrm{PF}$ providenciou material ${ }^{4} \mathrm{e}$ fez aplicação do jogo com o grupo investigado. Esse jogo estimula o processo de contagem, pois os alunos 
lançam bolinhas no colega, de forma a acertar o alvo. Com isso, uma brincadeira é gerada com o objetivo de contar quantas bolinhas cada um acertou.

Figura 2 - Aluno arremessando bolinha de isopor no alvo determinado

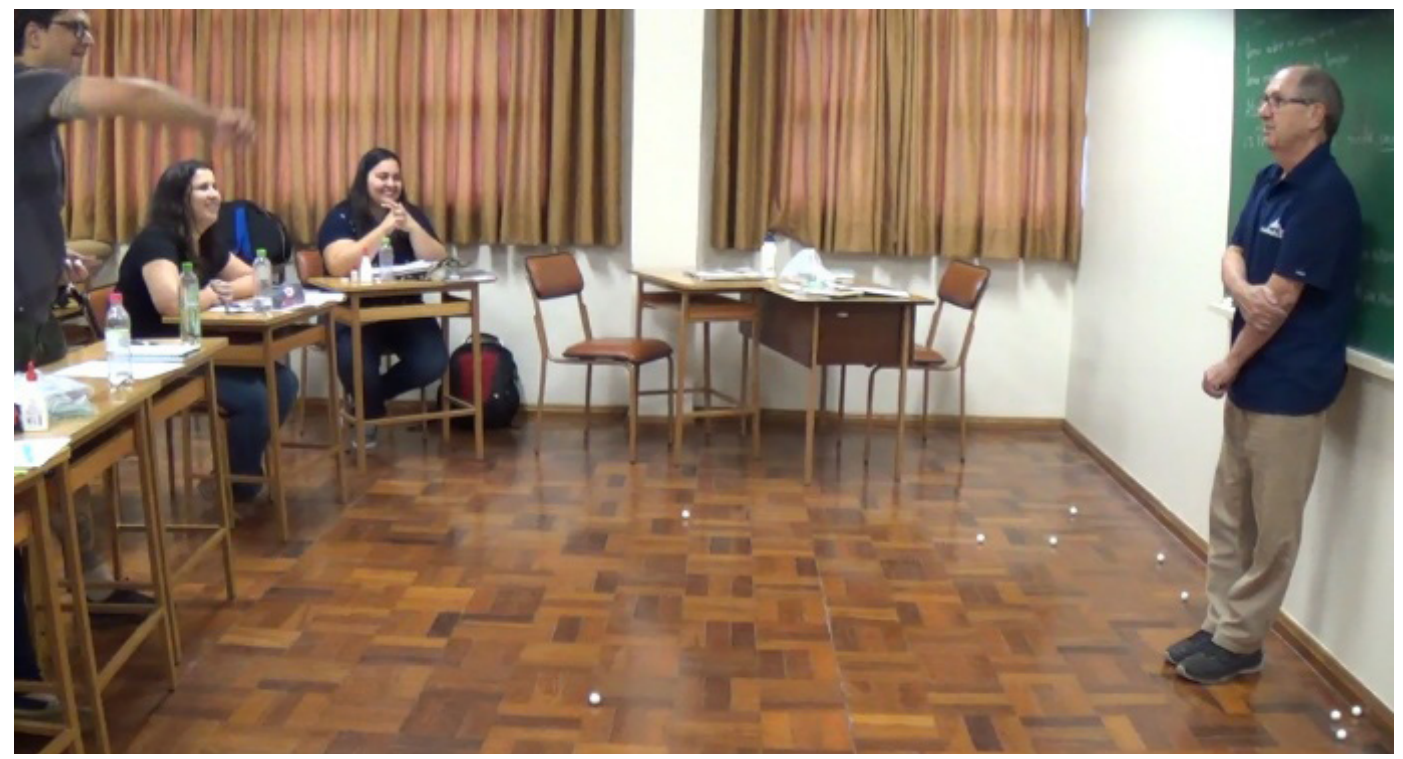

Fonte: dados da pesquisa, 2019.

Ao aplicar essa atividade, um participante se disponibilizou a lançar bolinhas de isopor no PF e a contar quantos acertos obteve. Repetiu-se a atividade com mais dois PPs.

Os PPs mencionaram qual seria a reação dos alunos dos anos iniciais, ou seja, o que usariam em termos de "mais" ou "menos" bolinhas no processo de contagem.

\section{Recurso didático para medir}

Outro item usado nesse episódio, com relação ao conhecimento do recurso didático, refere-se à Figura 3 (atividade 6), denotando algumas unidades de medidas. 
Figura 3 - Representação de outras formas de medir

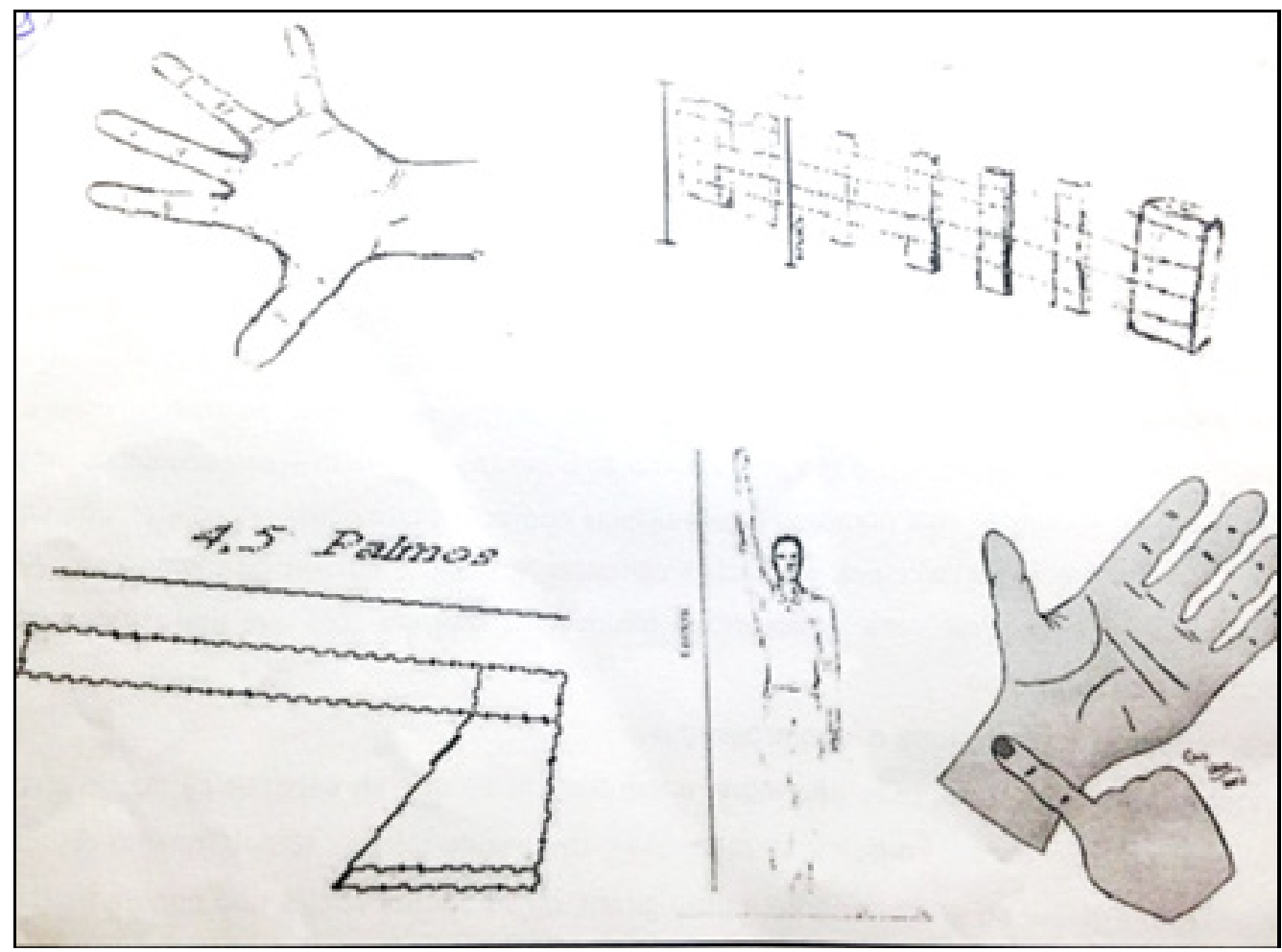

Fonte: Leivas (2002, p. 19).

De acordo com a Figura 3, é possível visualizar outras maneiras de medir, como o palmo, o mourão de cerca, entre outras, as quais são utilizadas por muitos povos. Porém, ao analisar tais medidas, os estudantes percebem que chegará o momento em que precisarão ter uma unidade de medida padrão. Por exemplo, no que se refere ao palmo, o de uma criança é diferente do de um adulto. Sendo assim, o aluno se questiona qual é a medida padrão a ser utilizada. Essa atividade surgiu como ponto de partida para discussões a respeito de unidades de medidas. No que tange ao exercício profissional, Mizukami (2004) menciona que os professores constroem um novo tipo de conhecimento, o qual é melhorado e enriquecido por outros tipos. De acordo com a autora, esse conhecimento:

[...] incorpora os aspectos do conteúdo mais relevantes para serem estudados [...] [e] também inclui uma compreensão do que torna a aprendizagem de tópicos específicos fácil ou difícil: as concepções e pré concepções que estudantes de diferentes idades e repertórios trazem para as situações de aprendizagem (MIZUKAMI, 2004, p. 6). 
Sendo assim, à medida que o professor exerce sua profissão, ele constrói conhecimentos que são aprimorados. Com esses novos conhecimentos, o profissional será capaz de transformar ou transpor o conhecimento científico, oriundo da academia, em conhecimento para o ensino, de modo que seja compreensível para seus alunos (CHEVALLARD, 2005).

\section{Considerações finais}

Para a presente pesquisa, partimos dos estudos de Shulman sobre o conhecimento exclusivo do professor, o conhecimento pedagógico e o conhecimento do conteúdo, avançando também em um maior aprofundamento teórico, por parte da pesquisadora, com relação a essas duas perspectivas. Pelo fato de o conhecimento pedagógico do conteúdo ocorrer de forma natural pela experiência, acreditamos que possa ser favorecido e aperfeiçoado em formações continuadas futuras, uma vez que é possível ter um acompanhamento dos professores em suas práticas. Logo, se faz necessário o envolvimento de professores em cursos específicos, que estimulem o desenvolvimento do conhecimento pedagógico do conteúdo.

O conhecimento pedagógico do conteúdo está em fase de desenvolvimento para os PPs, conhecimento essencial do papel docente, pois está ligado à sua atuação enquanto mediador na construção do conhecimento do aluno. Para a construção desse conhecimento, é preciso que o professor exerça um domínio do conteúdo específico, a fim de saber qual a forma que melhor se adapta ao seu ensino. Ou seja, o professor precisa ter uma compreensão do que é necessário para ensinar determinado conceito. Um fator fundamental que auxiliou os PPs na pesquisa para a construção do conhecimento pedagógico do conteúdo foi a reflexão de estar no lugar do aluno, isto é, os PPs recorriam a possíveis estratégias que um aluno dos anos inicias poderia utilizar ao resolver as atividades propostas na formação continuada, o que resultou em discussões e benefícios significativos para o ensino.

Esse conhecimento, exclusivo do professor, está inserido nas concepções que o docente percebe nas dificuldades de aprendizagens dos alunos, bem como na percepção da sua compreensão de um assunto específico, o que inclui acertos e erros cometidos pelos estudantes. Sendo assim, o professor necessita conhecer outras formas de representar o conteúdo que ele quer ensinar a seus alunos. Essas representações variadas são concebidas por pesquisas e práticas docentes. 
Finalizamos com a ideia de que, ainda que o professor não tenha experiências na sua área de atuação, o conhecimento pedagógico de conteúdo pode ser favorecido, desde que ele tenha acompanhamento de outros professores experientes, como é o caso do presente estudo. Nesta pesquisa, realizada em um curso de formação continuada voltada para o desenvolvimento do conhecimento pedagógico do conteúdo, a experiência de alguns participantes que atuaram na educação infantil e nos anos iniciais do ensino fundamental foi preponderante para o sucesso da aula e dos docentes que participaram da pesquisa.

\section{Pedagogical knowledge of content in education of elementary geometry: concept of measurement}

\section{Abstract}

This article is a cut of a Master's thesis that had as objective to analyze what contributions that a space of continuous formation of teachers of Mathematics can provide in the construction of the pedagogical knowledge of the content in Elementary Geometry. The theoretical basis selected for the work is centered on the knowledge base of the teacher needed for teaching, especially the pedagogical content knowledge (PCK), proposed by David Lee Shulman $(1986,1987)$. In order to carry out the research, we had the collaboration of a group of six professors (including the researcher herself), who were enrolled in the course: Mathematics in the Beginning Years: contents and production of activities of the Postgraduate Program of Science and Mathematics teaching. The complexity of the PCK, and the fact that it was built in real classroom situations, made it difficult for teachers who did not have experience in early year's education. However, we believe it is possible to provide them with a "favorable condition" for the construction and development of the PCK in formations that instil this knowledge. We conclude that the courses requiring the teacher to reflect and contemplate mathematical knowledge together with the pedagogical knowledge of the content can contribute in a satisfactory and positive way in the teaching and learning of the teacher, since the teacher does not only learn what to teach, but also how teach.

Keywords: Teaching of Geometry. Teacher training. Measure.

\section{Notas}

1 Aqueles que entendem: crescimento do conhecimento (1986) e Conhecimento e ensino: fundamentos da nova reforma (1987).

2 Os momentos gravados em vídeos foram registrados nos encontros da disciplina. Optamos por nomeá-los como "episódios".

3 Termo regional que corresponde a uma estaca de concreto, madeira ou pedra, que serve para construir uma cerca. Para isso, prende-se essa estaca, perpendicularmente, ao solo e, sobre ela, amarram-se telas, arames, placas de madeiras e outros materiais.

4 Nessa atividade, o PF trouxe o recurso didático para uso, isto é, as bolinhas de isopor. 


\section{Referências}

AMÁlGAMA. In: DICIO. Dicionário Online de Português. Porto: 7Graus, 2018. Disponível em: https://www.dicio.com.br/pesquisa.php?q=AM\%C1LGAMA. Acesso em: 16 abr. 2019.

CHEVALLARD, Yves. La transposición didática. 3. ed. 2. reimpr. Buenos Aires: Aique Grupo Editor, 2005.

LEIVAS, José Carlos Pinto. Um estudo etnomatemático. Educação Matemática em Revista, Rio Grande do Sul, v. 1, n. 4, p. 17-22, 2002.

MIZUKAMI, Maria da Graça Nicoletti. Aprendizagem da docência: algumas contribuições de L. Shulman. Revista do Centro de Educação (Universidade Federal de Santa Maria), Santa Maria, v. 29 , n. 2 , p. $33-49,2004$.

PIAGET, Jean. Seis estudos de Psicologia. Rio de Janeiro: Forense, 1977.

PONTE, João Pedro da Ponte; SERRAZINA, Maria de Lurdes. Didáctica da matemática do Ciclo I. Lisboa: Ed. Universidade Aberta, 2000.

PUENTES, Roberto Valdés; AQUINO, Orlando Fernández; QUILLICI NETO, Armindo. Profissionalização dos professores: conhecimentos, saberes e competências necessários à docência. Educar, Curitiba: Editora UFPR, n. 34, p. 169-184, 2009.

SERRAZINA, Maria de Lurdes. Conhecimento matemático para ensinar: papel da planificação e da reflexão na formação de professores. Revista Eletrônica de Educação, São Carlos, SP: UFSCar, v. 6 , n. 1 , p. 266-283, maio 2012 .

SHULMAN, Lee. Those who understand: knowledge growth in the teaching. Educational Researcher, Washington, US, v. 15, n. 2, p. 4-14, 1986.

SHULMAN, Lee. Knowledge and teaching: foundations of the new reform. Harvard Educational Review, Cambridge, US, v. 57, n. 1, p. 1-22, 1987.

SHULMAN, Lee. Renewing the pedagogy of teacher education: the impact of subjectspecific conceptions of teaching. In: MESA, L. Montero; JEREMIAS, J. M. Vaz. Las didácticas específicas en la formación del profesorado. Santiago de Compostela: Tórculo, 1992. p. 53-69.

SHULMAN, Lee. Conocimiento y enseñanza: fundamentos de la nueva reforma. Profesorado Revista de Currículum y Formación del Profesorado, Granada, a. 9, n. 2, p. 1-30, 2005.

TAHN, Malba. O homem que calculava. 48. ed. Rio de Janeiro: Record, 1999. 